\title{
Interest of Anorectal Manometry During Long-term Follow-up of Patients Operated on for Hirschsprung's Disease
}

\author{
Viet Q Tran, ${ }^{1,2 *}$ Tania Mahler, ${ }^{3}$ Patrick Bontems, ${ }^{3}$ Dinh Q Truong, ${ }^{1}$ Annie Robert, ${ }^{4}$ Philippe Goyens, ${ }^{5}$ and Henri Steyaert ${ }^{2}$ \\ ${ }^{1}$ Department of Pediatric Surgery, City Children's Hospital, Ho Chi Minh City, Vietnam; Departments of ${ }^{2}$ Pediatric Surgery and ${ }^{3}$ Gastroenterology, \\ Hôpital Universitaire des Enfants Reine Fabiola - Université Libre de Bruxelles (ULB), Brussels, Belgium; ${ }^{4}$ Faculté de santé publique, Institut de \\ Recherche Expérimentale et Clinique (IREC), Pôle de recherche EPID Epidémiologie et Biostatistique - Université catholique de Louvain (UCL), \\ Brussels, Belgium; and ${ }^{5}$ Laboratory of Pediatrics, Université Libre de Bruxelles (ULB), Brussels, Belgium
}

\section{Background/Aims}

Although many advances in the management of Hirschsprung's disease have recently been achieved, postoperative outcomes of these patients remain difficult in a non-negligible number of cases. Therefore, this study aims at investigating characteristics of anorectal manometry and its relationship with postoperative outcomes during long-term follow-up in Hirschsprung patients.

\section{Methods}

Patients over 4 years of age operated on for Hirschsprung's disease were interviewed to complete detailed questionnaires on bowel function. The patients who consented to undergo an anorectal manometry during follow-up were enrolled in this study. We investigated their clinical characteristics, manometric findings, and their postoperative bowel function.

\section{Results}

Nineteen patients out of 53 patients (35.8\%) were enrolled, $68.4 \%$ who were male. Mean age of patients at manometry was $11.3 \pm$ 6.3 years. Twelve out of 19 patients (63.2\%) were incontinent. The mean anal resting pressures of incontinent patients were significantly lower than continent patients ( $47 \pm 12 \mathrm{mmHg}$ versus $63 \pm 11 \mathrm{mmHg}, P<0.05, t$ test). Due to neurological impairment, only 11 patients (57.9\%) were able to perform a complete manometry. A dyssynergic defecation was found in 4 patients during strain tests. Maximum tolerated volume of the incontinent patients was significantly lower than that of the continent patients $(97 \pm 67 \mathrm{~mL}$ versus $181 \pm 74 \mathrm{~mL}, P<0.05, t$ test).

\section{Conclusion}

Anorectal manometry is an objective method providing useful information that could guide a more adapted management in patients with defecation disorders after Hirschsprung's disease operation.

\section{(J Neurogastroenterol Motil 2018;24:70-78)}

Key Words

Defecation; Follow-up studies; Hirschsprung disease; Manometry; Postoperative period

Received: February 15, 2017 Revised: May 25, 2017 Accepted: July 12, 2017

(a) This is an Open Access article distributed under the terms of the Creative Commons Attribution Non-Commercial License (http://creativecommons. org/licenses/by-nc/4.0) which permits unrestricted non-commercial use, distribution, and reproduction in any medium, provided the original work is properly cited.

*Correspondence: Viet Q Tran, MD Department of Pediatric Surgery, Hôpital Universitaire des Enfants Reine Fabiola - Université Libre de Bruxelles (ULB), Avenue JeanJoseph Crocq 151020 Brussels, Belgium Tel: +84-909-490-527, Fax: +84-2-822-538-899, E-mail: dr.tranquocviet@gmail.com 


\section{Introduction}

Hirschsprung's disease (HD) is the most common congenital malformation of the enteric nervous system in children. Although there are many recent advances related to surgical techniques, postoperative outcomes remain variable. ${ }^{1}$ Defecation disorders may happen after surgery for HD. Fecal incontinence and constipation are the 2 main complaints in the long-term outcome. ${ }^{2}$

However, a clinically accurate assessment of continence is often difficult to obtain. In the literature, authors report wide ranges of fecal incontinence. ${ }^{3-7}$ Continence problems may be due to either a primary motility disorder or sequelae of the surgical techniques. ${ }^{8}$ To clarify and to understand the importance of these different mechanisms, the pathophysiology of defecation has to be studied. It has been suggested that anorectal manometry could help objectify and distinguish between functional disorders and acquired troubles. ${ }^{9-13}$ Otherwise little is known about anorectal manometry in patients after surgery for HD., ${ }^{9,10,14,15}$ Therefore, this study aims at investigating anorectal manometry findings of patients operated on for $\mathrm{HD}$ and the relationship with their outcomes.

\section{Materials and Methods}

\section{Study Design}

This study was conducted at the Hôpital Universitaire des Enfants Reine Fabiola, Brussels, Belgium and was approved by the research ethics committee of the hospital (CEH 2014-41). All consecutive charts of patients operated on for HD in our department between 1987 and 2010 were retrieved. Demographic and clinical data were retrieved on gender, date of birth, age at surgery, type of operation, enterostomy, operative complications, resected colon segment, and neurological status. Patients over 4 years of age at the time of the study received a letter detailing the planned study and were invited to perform an anorectal manometry as well as to participate in a study on long-term outcome. All manometric findings were collected for analysis in this study.

\section{Fecal continence}

Fecal continence was based on the Wingspread classification, which defines the following 4 levels of continence: excellent, very good: clean (totally continent, toilet trained with no medication); good: staining (rarely soiling, except during stressful exercise); fair: intermittent fecal soiling, urge incontinence; poor: constant fecal soiling or smearing. ${ }^{16}$ Patients classified as "fair" or "poor" were considered as fecally incontinent; the other categories were considered as fecally continent. Fecal continence was considered to have been acquired normally in children older than 4 years. ${ }^{17}$

\section{Constipation}

Patients were interviewed for stooling frequency, use of laxatives and enema over the months preceding investigation. A patient was considered as suffering from constipation if defecation was only possible with laxatives, or occurred less than 3 times per week, according to the Rome III criteria for functional constipation. ${ }^{18}$

\section{Enterocolitis}

History of enterocolitis was reviewed and classified on a scale (none, single time or several times) from medical records as well as at interview for each patient.

\section{Operative procedures}

Initially, Soave pull-through with abdominal approach (open Soave) was used in our institution. More recently, transanal endorectal pull-through with or without laparoscopic assistance (minimally invasive surgery Soave) was used. In cases of severe enterocolitis or failure with nursing care (wash-out) before pull-through operation, an enterostomy was performed. For patients with total colon aganglionosis, an ileoanal anastomosis without reservoir was done.

\section{Anorectal manometry}

An electrically powered anorectal manometry Medtronic system (serial number: MS4-1867, model number PIP-4-8; Medtronic, Minneapolis, MN, USA) and 14 Fr water perfused catheters with 8 channels were used. An enema (Fleet enema for children with dosage of $3 \mathrm{~mL} / \mathrm{kg}$ or in some cases with nursing enema by sodium chloride $0.9 \%$ solution) was routinely administered prior the test. In addition, a bowel management at least 1 week before the test was taken to facilitate rectal emptying in cases with fecal impaction.

Patients were in the supine position, with the hips and knees flexed. The motility probe and balloon were well lubricated. The patient was asked to lie still, relaxed, and silent as much as possible, and the test started just when an enough familiarization was achieved to insert the probe. Toys, distraction, and relaxation were used to facilitate the examination.

Depending on the ability of cooperation, based mainly on age and neurological status of the patients at investigation, patients were asked to perform consecutive steps of the test, as described below 
in the section on the profile of anorectal manometry. In this study, patients with chromosomal syndrome (Down's syndrome and 13q deletion syndrome) were considered as neurologically impaired. A "complete anorectal manometry" was performed when cooperative patients had full capacity to undergo all the steps. Otherwise in noncooperative patients, only the 2 first steps investigating "anal resting pressure" and "recto-anal inhibitory reflex" were done, therefore considered as an "incomplete anorectal manometry."

\section{Profile of Anorectal Manometry}

\section{Anal resting pressure}

At the beginning of the test, a minimum 3-minute familiarization period was undertaken. After this time, the anal resting pressure was recorded. With the patient at rest, anal pressure was measured during 20 seconds; the minimum and maximum values were recorded ( $\mathrm{mmHg})$.

\section{Recto-anal inhibitory reflex}

The balloon was inflated within 3-5 seconds and subsequently deflated; the initial volume was $10 \mathrm{~mL}$, and was subsequently increased by increments of $10 \mathrm{~mL}$. This test was repeated until a volume of $60 \mathrm{~mL}$ was obtained to detect the presence of the rectoanal inhibitory reflex (RAIR) represented by a transient reduction of anal pressure within the inner zone of the anal canal, due to relaxation of the internal anal sphincter after a rapid distention of the rectum by inflation of the balloon. ${ }^{19}$ In this study a RAIR was reported as positive if the amount of this reduction was over one third of the preceding anal pressure value.

\section{Voluntary maneuvers (when possible)}

(1) Coughing maneuver, patients were asked to do 2 single coughs; (2) squeeze maneuver, 2 squeezes of 5 second duration; and (3) endurance squeeze, 2 episodes of squeeze for 20 seconds in duration. The voluntary maneuvers were reported as normal if patients presented with appropriate increases of anal pressure according to their ages in amplitude as well as in duration. An interval time of 20 seconds was routinely required after each maneuver.

\section{Sensation test (when possible)}

The balloon was inflated at a rate of $5 \mathrm{~mL}$ every 5 seconds and the patient was asked to consequently report: first sensation, desire to defecate, and finally a maximum tolerated volume when intense urge to defecate or an abnormal painful rectal sensation appeared were noted. ${ }^{19}$

\section{Balloon expulsion test (when possible)}

During the final step of the test, the balloon was filled with 10$20 \mathrm{~mL}$ of air according to their ages and the patient was then asked to bear down in an attempt to expel the balloon. While the patient tried to evacuate the balloon, we measured the rectal pressure and anal sphincter pressure. Normally, the anal sphincters (internal and external) have to relax at the time of defecation. Failure to evacuate the balloon with paradoxical increase of anal sphincter pressure indicates a dyssynergic defecation. ${ }^{19}$

\section{Statistical Methods}

Data were reported as mean and standard deviation or median and range for continuous variables, according to their distribution, and as number and proportion for categorical variables. The chi-square test or the Fischer exact test was used to compare proportions, and the independent $t$ test was used to compare means. All tests were two-sided and a $P$-value $<0.05$ was considered as significant. IBM SPSS Statistics version 20 (IBM Corp, Armonk, NY, USA) was used for statistical analysis.

\section{Results}

Out of 58 consecutive patients operated on for HD in our hospital, 53 (91.4\%) accepted to participate in a long-term outcome survey, whereas the 5 remaining patients have been lost to followup. All patients had a histopathological confirmation of $\mathrm{HD}$ and a normal ganglionic innervation at the level of anastomosis. As the results of the survey regarding 53 patients, prevalence of fecal incontinence was $22.6 \%$ (12 patients) and $13.2 \%$ (7 patients) for constipation.

Nineteen patients consented to undergo an anorectal manometry and were therefore enrolled in this present study. The demographic and clinical findings of these 19 patients and the 34 others who did not consent to undergo an anorectal manometry are shown in Table 1. There were significant differences between the patients with anorectal manometry and the patients without an anorectal manometry in terms of the age of patients, the operative procedure, and the prevalence of fecal incontinence. No other significant difference was found in terms of neurological status, history of enterostomy, length of resected colon, episodes of enterocolitis, postoperative complication, as well as constipation.

Table 2 shows the characteristics of the 19 patients with anorectal manometry according to their fecal continence status. Mean age of the patients at anorectal manometry was $11.3 \pm 6.3$ years. 
Table 1. Patient Characteristics and Defecation Patterns of the 53 Patients With and Without Anorectal Manometry After Surgical Management for Hirschsprung's Disease at Investigation

\begin{tabular}{lcccc}
\hline & With & Without \\
Patient characteristics & $\mathrm{N}$ & $\mathrm{AM}$ & $\mathrm{AM}$ & $P$-value \\
& & $\mathrm{n}(\mathrm{n} / \mathrm{N}, \%)$ & $\mathrm{n}(\mathrm{n} / \mathrm{N}, \%)$ & \\
\hline
\end{tabular}

Age (mean $\pm \mathrm{SD}$, yr) $\quad 16.1 \pm 7.6 \quad 11.3 \pm 6.3 \quad 18.8 \pm 7.0<0.001$ Age groups (yr)

$\begin{array}{lrrrr}>4,<10 & 12 & 8(66.7) & 4(33.3) & \\ 10-16 & 13 & 5(38.5) & 8(61.5) & \\ >16 & 28 & 6(21.4) & 22(78.6) & \\ \text { Gender } & & & & >0.999 \\ \text { Male } & 36 & 13(36.1) & 23(63.9) & \\ \text { Female } & 17 & 6(35.3) & 11(64.7) & \end{array}$

Neurological status

NI patients

Non-NI patients

Enterostomy

Yes

No

Resected colon

Recto-sigmoid colon

Descending colon

Transverse colon

Total colon

Operative procedure

\begin{tabular}{|c|c|c|c|c|}
\hline \\
\hline Open Soave & 40 & $11(27.5)$ & $29(72.5)$ & \\
\hline MIS Soave & 13 & $8(61.5)$ & $5(38.5)$ & \\
\hline \multicolumn{4}{|l|}{ Enterocolitis } & $>0.999$ \\
\hline No & 44 & $16(36.4)$ & $28(63.6)$ & \\
\hline Single time & 5 & $2(40.0)$ & $3(60.0)$ & \\
\hline Several times & 4 & $1(25.0)$ & $3(75.0)$ & \\
\hline \multicolumn{5}{|c|}{ ostoperative complications ${ }^{a}$} \\
\hline Anastomotic leak & 3 & 2 & 1 & \\
\hline Bowel obstruction & 3 & 1 & 2 & \\
\hline Twisted colon & 1 & 1 & 0 & \\
\hline Residual aganglionosis & 1 & 0 & 1 & \\
\hline Total complication & 8 & 4 & 4 & 0.436 \\
\hline Fecal incontinence & & & & $<0.001$ \\
\hline Yes & 12 & $12(100.0)$ & $0(0.0)$ & \\
\hline No & 41 & $7(17.1)$ & $34(82.9)$ & \\
\hline Constipation & & & & 0.691 \\
\hline Yes & 7 & $3(42.9)$ & $4(57.1)$ & \\
\hline No & 46 & $16(34.8)$ & $30(65.2)$ & \\
\hline Total & 53 & $19(35.8)$ & $34(64.2)$ & \\
\hline
\end{tabular}

${ }^{a}$ Postoperative complications reported by number of encountered cases. AM, anorectal manometry; NI, neurologically impaired; MIS Soave, minimally invasive surgery Soave includes transanal endorectal pull-through with or without laparoscopic assistance.
Table 2. Patient Characteristics of the 19 Patients Who Consented to Undergo an Anorectal Manometry According to Their Fecal Continence Status at Investigation

\begin{tabular}{|c|c|c|c|c|}
\hline Variables & $\mathrm{N}$ & $\begin{array}{l}\text { Continence } \\
\mathrm{n}(\mathrm{n} / \mathrm{N}, \%)\end{array}$ & $\begin{array}{c}\text { Incontinence } \\
\mathrm{n}(\mathrm{n} / \mathrm{N}, \%)\end{array}$ & $P$-value \\
\hline Age (mean $\pm \mathrm{SD}, \mathrm{yr})$ & $11.3 \pm 6.3$ & $12.7 \pm 6.0$ & $10.3 \pm 6.6$ & 0.441 \\
\hline Age groups (yr) & & & & 0.833 \\
\hline$>4-10$ & 8 & $2(25.0)$ & $6(75.0)$ & \\
\hline $10-16$ & 5 & $2(40.0)$ & $3(60.0)$ & \\
\hline$>16$ & 6 & $3(50.0)$ & $3(50.0)$ & \\
\hline Gender & & & & $>0.999$ \\
\hline Male & 13 & $5(38.5)$ & $8(61.5)$ & \\
\hline Female & 6 & $2(33.3)$ & $4(66.7)$ & \\
\hline Neurological status & & & & 0.106 \\
\hline NI patients & 5 & $0(0.0)$ & $5(100.0)$ & \\
\hline Non-NI patients & 14 & $7(50.0)$ & $7(50.0)$ & \\
\hline Enterostomy & & & & 0.603 \\
\hline Yes & 15 & $5(33.3)$ & $10(66.7)$ & \\
\hline No & 4 & $2(50.0)$ & $2(50.0)$ & \\
\hline Resected segment & & & & 0.702 \\
\hline Classic recto-sigmoid form & 15 & $5(33.3)$ & $10(66.7)$ & \\
\hline Long segment forms ${ }^{a}$ & 4 & $2(50.0)$ & $2(50.0)$ & \\
\hline Operative procedure & & & & 0.633 \\
\hline Open Soave & 11 & $5(45.5)$ & $6(54.5)$ & \\
\hline MIS Soave & 8 & $2(25.0)$ & $6(75.0)$ & \\
\hline Enterocolitis & & & & $>0.999$ \\
\hline Yes & 3 & $1(33.3)$ & $2(66.7)$ & \\
\hline No & 16 & $6(37.5)$ & $10(62.5)$ & \\
\hline Postoperative complication & & & & 0.603 \\
\hline Yes & 4 & $2(50.0)$ & $2(50.0)$ & \\
\hline No & 15 & $5(33.3)$ & $10(66.7)$ & \\
\hline Constipation & & & & 0.263 \\
\hline Yes & 3 & $0(0.0)$ & $3(100.0)$ & \\
\hline No & 16 & $7(43.8)$ & $9(56.2)$ & \\
\hline Total & 19 & $7(36.8)$ & $12(63.2)$ & \\
\hline
\end{tabular}

${ }^{\mathrm{a}}$ Long segment form includes the cases with descending, transverse, and total colon aganglionosis.

NI, neurologically impaired; MIS Soave, minimally invasive surgery Soave includes transanal endorectal pull-through with or without laparoscopic assistance.

Among them, 12 patients $(63.2 \%)$ presented with fecal incontinence; of note, 3 of those patients reported frequent fecal soiling as well as constipation on the questionnaire. The last 7 patients did not present any defecation problems. Five patients had a chromosomal syndrome (4 with Down's syndrome and one with 13q deletion syndrome) and were considered as neurologically impaired. The mean age of neurologically impaired patients was significantly younger than the others $(7.2 \pm 3.2$ years versus $13.3 \pm 6.3$ years, $P<0.05$, $t$ test). The neurologically impaired patients had a higher prevalence 
Table 3. Manometric Findings of the 19 Patients Who Consented to Undergo an Anorectal Manometry According to Their Fecal Continence Status at Investigation

\begin{tabular}{|c|c|c|c|c|}
\hline Manometric findings & $\mathrm{N}$ & Continence & Incontinence & $P$-value \\
\hline Anal resting pressure (mean $\pm \mathrm{SD}, \mathrm{mmHg})$ & & $63 \pm 11$ & $47 \pm 12$ & 0.009 \\
\hline Reappearance of RAIR (n [n/N, \%]) & & & & 0.377 \\
\hline Yes & 8 & $4(50.0)$ & $4(50.0)$ & \\
\hline No & 11 & $3(27.3)$ & $8(72.7)$ & \\
\hline Patients with a complete $\mathrm{AM}^{\mathrm{a}}(\mathrm{n})$ & 11 & 6 & 5 & \\
\hline \multicolumn{5}{|l|}{ Voluntary maneuvers ${ }^{\mathrm{b}}$} \\
\hline Cough maneuver & & 6 & 5 & - \\
\hline Squeeze maneuver & & 6 & 5 & - \\
\hline Endurance squeeze & & 6 & 5 & - \\
\hline \multicolumn{5}{|l|}{ Sensation test (mean $\pm \mathrm{SD}, \mathrm{mL})$} \\
\hline First urge & & $108 \pm 79$ & $53 \pm 20$ & 0.149 \\
\hline Maximum tolerated volume & & $181 \pm 74$ & $97 \pm 67$ & 0.021 \\
\hline Dyssynergic defecation $^{c}$ & 4 & 2 & 2 & $>0.999$ \\
\hline
\end{tabular}

${ }^{a}$ A complete anorectal manometry (AM) was performed when cooperative patients had full capacity to undergo all the steps.

${ }^{b}$ Data for cough, squeeze, and endurance squeeze presented by numbers of encountered cases with a normal test.

Data reported by number of encountered cases.

RAIR, recto-anal inhibitory reflex.

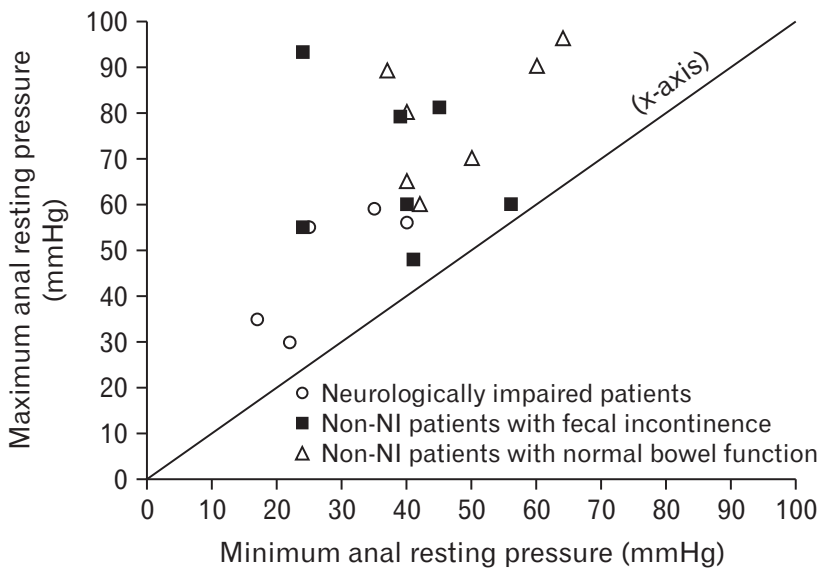

Figure 1. Measurements of anal resting pressure $(n=19)$. Vertical axis represents maximum anal resting pressure; horizontal axis represents minimum anal resting pressure. Note the anal resting pressure lower than $60 \mathrm{mmHg}$ in all 5 neurologically impaired (NI) patients (circle dots) and the tendency to be closer to the bisector (labelled as the $\mathrm{x}$-axis). The closer the dot to the bisector, the smaller the difference between the maximum and the minimum anal resting pressure of the case.

of fecal incontinence than the patients without neurological impairment; but the difference was not significant $(P>0.05)$. No other characteristic of patients was significantly associated with fecal incontinence, although there was a tendency of higher association with fecal incontinence in cases with the minimally invasive surgery Soave technique, episodes of enterocolitis, and postoperative complications.

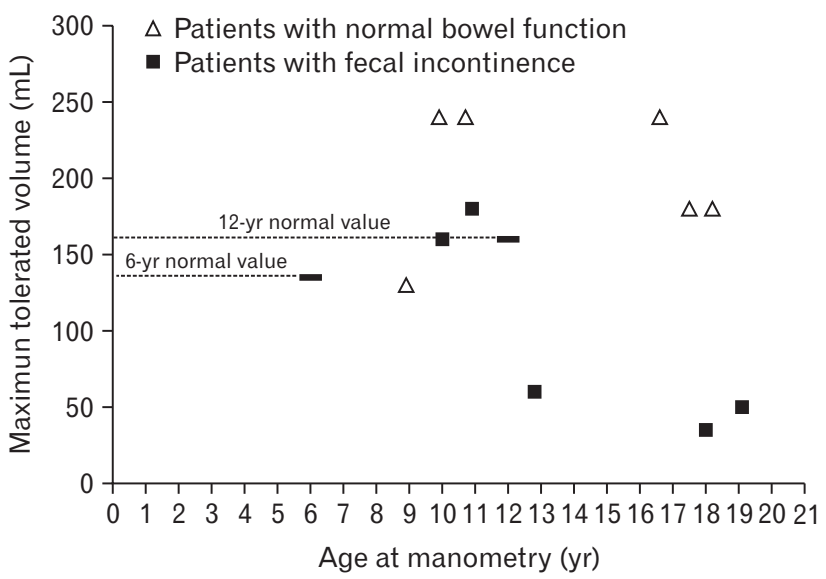

Figure 2. Maximum tolerated volume measurements related to ages of patients who performed a sensation test $(n=11)$. The dotted lines represent the normal values: $135 \mathrm{~mL}$ in children 6 years of age and $160 \mathrm{~mL}$ in children 12 years of age. Adapted from Meinds et al. ${ }^{10}$

\section{Manometric Findings}

Regarding the 19 patients who underwent an anorectal manometry, Table 3 shows the manometric findings of continent patients compared with incontinent patients.

Anal resting pressure of incontinent patients was significantly lower than continent patients $(47 \pm 12 \mathrm{mmHg}$ versus $63 \pm 11$ $\mathrm{mmHg} ; P<0.05, t$ test). The distribution of patients' anal resting pressure stratified by their neurologic and fecal continence status is shown in Figure 1. 


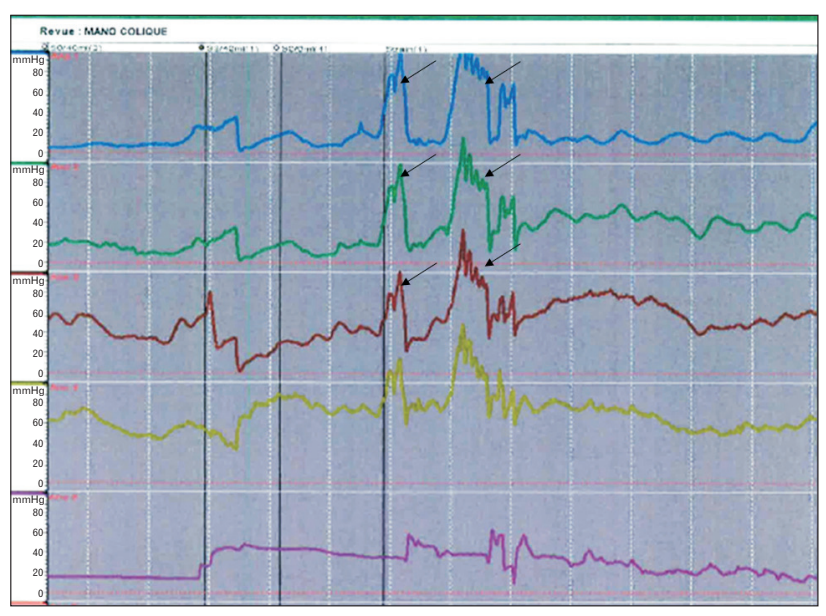

Figure 3. Anorectal manometry diagram demonstrating inappropriate increases in anal sphincter pressure (black arrows) during strain maneuvers, considered to be dyssynergic defecation. The figure shows the case of an 8-year-old boy, operated on for Hirschsprung's disease with open Soave. His chief complaint was grade 3 fecal soiling according to the Wingspread classification. The patient underwent a bowel management with laxatives (polyethylene glycol) with good results. Of note, a significant fecal impaction was revealed after consultation suggesting an "overflow incontinence."

Eight out of 19 patients (42.1\%) showed a relaxation reflex within the internal part of the anal sphincters that was considered as a reappearance of RAIR.

As ability of cooperation depended basically on the age and neurological status of the patients, only 11 out of 19 patients (57.9\%) were able to perform a complete anorectal manometry as shown in Table 3. The cough, squeeze, and squeeze duration maneuvers were normal in all of these patients. Patients with fecal incontinence demonstrated a significant decrease of the maximum tolerated volume according to their age $(97 \pm 67 \mathrm{~mL}$ for incontinent patients compared to $181 \pm 74 \mathrm{~mL}$ for continent patients, $P<0.05$ ). The maximum tolerated volume of these patients during sensation test are shown in detail in Figure 2.

During the strain maneuver, 4 patients showed dyssynergic defecation patterns as illustrated in Figure 3. Two of them clinically presented with significant fecal impaction at investigation and had better outcomes after a bowel management.

\section{Discussion}

Surgical treatment of HD consists of resecting the aganglionic bowel segment followed by anastomosis of the normally innervated bowel to the anus. However, it is well established that patients operated on for HD are clinically at high risk of defecation disorders. ${ }^{2,20,21}$ Indeed, the Soave procedure- a worldwide used technique as well as in our series-was developed specifically to leave a muscular cuff outside of the rectal wall in order to protect the surrounding structures from damage by performing an endorectal dissection. As a consequence, the longer the cuff, the higher incidence of obstructive symptoms sometimes result in overflow incontinence; whereas, the shorter the cuff, the higher incidence of fecal incontinence. ${ }^{22}$ Clinically, the differentiation between "true" incontinence due to the deficit of anal sphincters or an overflow incontinence resulting from a severe constipation, is therefore essential to obtain a better and more adapted management, but difficult to make. ${ }^{23}$

Anorectal manometry is considered an objective way to visualize anorectal function. However, there are few reports about anorectal manometry during follow-up of children operated on for HD, and its role still seems controversial in terms of the uses of different anorectal manometry systems (conventional versus high-resolution anorectal manometry [HRAM]), lack of normal value, particularly the reference value of HRAM in HD patients. ${ }^{9,10,14,15}$ Therefore, this study aimed at investigating the anorectal manometry findings in our patients after operation for $\mathrm{HD}$ while considering their longterm bowel function.

Regarding our long-term outcome survey, we report findings similar to those described in the literature, that is, defecation disorders remain problematic issues and challenges in a high percentage of the patients even until adulthood, significantly altering their quality of life, especially in cases with fecal incontinence. This could explain the high percentage of patients suffering from fecal incontinence who consented to our anorectal manometry survey (Table 1). They particularly need close medical attention to manage their fecal incontinence problems. ${ }^{24,25}$

\section{Anal Resting Pressure}

In regard with anal resting pressure, the internal anal sphincter and external anal sphincter contribute to $55.0 \%$ and $35.0 \%$ of the anal resting pressure, respectively; the remaining $15.0 \%$ originating from surrounding perineal anatomical structure. ${ }^{26}$ Therefore, a reduced anal resting sphincter pressure could be explained by an anal sphincter deficit, especially in HD patients who underwent a pull-through procedure. In the literature, several authors stated that patients with true incontinence present a significantly lower resting pressure than normal subjects. ${ }^{24,27}$ As also reported by Gad ElHak et $\mathrm{al}^{25}$ in a study of 52 patients after pull-through operation, the mean pressure was $58.1 \pm 15.1 \mathrm{mmHg}$ among continent cases, $49.1 \pm 15.1 \mathrm{mmHg}$ among minor incontinent cases, and $37.1 \pm$ 
$12.1 \mathrm{mmHg}$ among major incontinent cases with a highly significant difference between continent and major incontinent groups. On the other hand, Meinds et $\mathrm{al}^{10}$ reported a wide range of anal resting pressure 70 (25-110) $\mathrm{mmHg}$. Of note, the HRAM system with solid catheters was used in the study of Meinds et al, ${ }^{10}$ whereas the conventional polygraph anorectal manometry was used in the study of Gad El-Hak et al. ${ }^{25}$ In our study, anal resting pressure in incontinent patients was $47 \pm 12 \mathrm{mmHg}$ which was significantly lower than in continent patients with $63 \pm 11 \mathrm{mmHg}$ (Table 2). Regarding surgical treatment, there is an ongoing debate in the literature on whether the risk of fecal incontinence is associated with the operative technique. Overstretching during endorectal pullthrough by retractors can lead to injury of the anal sphincters. ${ }^{21}$

In our series, the NI patients tended to have a lower anal resting pressure and also demonstrated a high proportion of fecal incontinence, as shown in Figure 1. According to our knowledge there is no report in the literature mentioning a lower anal resting pressure in Hirschsprung patients with trisomy 21 than in normal subjects. Catto-Smith et $\mathrm{al}^{28}$ also reported a very high prevalence of fecal incontinence of $87.0 \%$ in children with Down's syndrome associated with Hirschsprung's disease. However, Powers et $\mathrm{al}^{29}$ reported as well that bowel continence in patients with Down's syndrome could appear at a later age than usual, and in our series they were significantly younger than the others. In fact, the management of NI patients is very difficult because of their attention deficit for either clinical or psychosocial aspects.

\section{Rectal Anal Inhibitory Reflex}

The reappearance of RAIR in patients operated on for $\mathrm{HD}$ is still controversial. Normally this reflex is absent in HD patients and, in the literature, most authors reported no RAIR in anorectal manometry during follow-up of the patients operated on for HD. ${ }^{10}$ In contrast, Mishalany et $\mathrm{al}^{9}$ and Moore et $\mathrm{al}^{11}$ reported RAIR reappearance in $10.0 \%$ and $13.6 \%$ of the operated patients for HD, respectively. Recently, Gad El-Hak et $\mathrm{al}^{25}$ reported RAIR becoming intact in $11.5 \%$ of the HD patients 4 years after operation as well as their improvement in rectoanal sensation. Interestingly, in our series, 8 out of 19 patients got their RAIR back. In fact RAIR is an intramural local axon reflex controlled by spinal and higher centers. ${ }^{30}$ So, it raised an hypothesis that the normally innervated bowel anastomosed to the anal canal acquires a "quite normal" rectal function as an adaptation of the neo-rectum years after a pull-through operation. ${ }^{25}$ However, re-establishment of RAIR was not clinically correlated with any positive long-term outcome in our series as well as in the other studies. ${ }^{9}$ Of course, a RAIR re-establishment due to technical issues should be always considered. ${ }^{18}$

\section{Voluntary Anorectal Manometry Maneuvers}

Regarding voluntary maneuvers including cough, squeeze, and endurance squeeze as illustrated in Table 2, the 11 full cooperative patients have witnessed an adequate increase of anal tonus in amplitude as well as in duration. These maneuvers are indicated to assess the integrity of spinal reflex pathways of the patients; normally, the increased abdominal pressure triggers voluntarily external sphincter contraction. ${ }^{26}$ As mentioned above, the complexity of anatomical perineal structures contribute also to the anal tonus. For that reason, voluntary anorectal manometry maneuvers are important for the rationale of biofeedback therapy in patients presenting a severe incontinence due to technically surgical problems. ${ }^{10,31}$

\section{Sensation Test}

Concerning the pathophysiology of fecal incontinence, rectal sensation and rectal compliance are the 2 essential determinants. In our series, the maximum tolerated volume in the incontinent patients was significantly lower than in continent patients (Table 2). As illustrated in Figure 2, there were 3 out of 5 patients with fecal incontinence with a sharp decrease of the maximum tolerated volume. Although we could not measure rectal compliance in these patients, the maximum tolerated volume indirectly provided helpful information about rectal sensation as well as elasticity and reserve capacity of the neo-rectum. ${ }^{26}$ Therefore, the hypothesis is raised that fecal incontinence could be due to rectal factors where the maximum tolerated volume is often impaired and below normal. ${ }^{32}$ Here again, technical surgical issues may be of concern. For example, there may be a twisted colon or tension on the inferior mesenteric artery when lowering the colon particularly during a fully transanal endorectal pull-through. This could lead to rectal stenosis and be the reason for postoperative obstructive symptoms accompanied by possible soiling or incontinence. ${ }^{33}$ For that reason we advocate the use of laparoscopic assistance, instead of open abdominal approach, in order to adequately dissect the colonic mesentery as well as minimize injury during perineal and anorectal dissection and avoiding eventual twist during lowering of the colon. ${ }^{34}$ To date, this is used routinely in our institution, as well as in many other centers worldwide. $^{35}$

\section{Dyssynergic Defecation}

Even if most postoperative outcomes of HD patients are explained by anatomical issues, some potential functional disorders may partially contribute to these problems as well. Meinds et $\mathrm{al}^{10}$ 
demonstrated that dyssynergic defecation aggravates the already troublesome defecation in patients after HD operation. In fact, the onset of dyssynergic defecation has been described in postoperative HD patients for a number of reasons. First, a high percentage of fecal soiling as well as an increase in defecation frequency after a pull-through operation could make patients more prone to developing dyssynergic defecation. ${ }^{10}$ Defecation is painful for most patients after HD surgery, especially in cases with additional treatment such as washouts, anal rectal dilation or sometimes a surgical redo procedure due to complications. They tend to therefore delay defecation for as long as possible. The more apprehensive they are, the more fecal impaction presents and a vicious cycle of pain and delay exists. Hyman ${ }^{36}$ suggested that these patients tend to avoid bowel movement because of the association with increased anorectal painful sensation. But Rao et a ${ }^{37}$ suggested that dyssynergic defecation symptoms are also seen in the general population, owing perhaps to their faulty learning of proper defecation during childhood. In these patients, the initial problem could be retentive constipation followed by an overflow incontinence. If not well managed, this process may sometimes result, again, in an irreversibly dilated incompetent colon, whereas this is, in the beginning, a reversible situation using an appropriate bowel management as well as biofeedback therapy. ${ }^{31} \mathrm{In}$ our series, there were 4 patients showing a dyssynergic defecation (Table 2) and 2 of them presented with significant fecal impaction.

Severe fecal incontinence remains the main determinant of decrease in quality of life in patients suffering from $\mathrm{HD}^{2}$. Therefore, a long-term follow-up by a multidisciplinary team including pediatric surgeons, gastroenterologists, dieticians as well as psychologists is essential. In some instances, if the troubles persist into adolescent or even into adulthood, close cooperation with an adult team specializing in fecal continence is recommended. In our long-term outcomes series, one patient who recently benefited from a sacral nerve stimulation device implantation was operated on by our pediatric surgical team together with an adult team before he was entrusted to the adult team. ${ }^{38,39}$ We believe this is an important transition for all cases now.

All the above therapeutic strategies should be carefully considered together with the anorectal manometry findings that provide very useful information regarding the actual origin of continence problems not always easy to be clinically distinguished, as reported in this present study. However, this study also had some limitations, for instance a conventional anorectal manometry system was used. Further studies need to be conducted in the future; now we continue with HRAM—a new trend in this field.

\section{Conclusions}

Our experiences show that anorectal manometry could be an objective method for investigating anorectal malfunction, providing useful findings in patients presenting with defecation disorders after HD operation. Anorectal manometry may help in decision making on a more objective manner than just clinical examination. Several types of anomalies may be detected leading the medical staff to an individually adapted bowel management or, if necessary, to an appropriate surgical option.

Financial support: This work is part of a PRD project (Projet de Recherche pour le Développement) focused on better understanding Hirschsprung's disease, granted by "Académie de Recherche et d'Enseignement Supérieur - Commission de la Coopération au Développement (ARES-CCD)" in Belgium (http://www.aresac.be/fr/cooperation-au-developpement).

\section{Conflict of interest: None.}

Author contributions: Viet Q Tran drafted this manuscript and received the feedback and revisions from the other co-authors; Tania Mahler is the main investigator for the anorectal manometry tests in this study and also the advisor of Viet Q Tran in this field; Viet Q Tran, Tania Mahler, and Henri Steyaert performed the collection and analysis of the data; and Patrick Bontems, Annie Robert, Philippe Goyens, and Dinh Q Truong contributed to the design of the study and to the critical revisions of the manuscript.

\section{References}

1. Nasr A, Langer JC. Evolution of the technique in the transanal pullthrough for Hirschsprung's disease: effect on outcome. J Pediatr Surg 2007;42:36-39; discussion, 39-40.

2. Teitelbaum DH, Coran AG. Long-term results and quality of life after treatment of Hirschsprung's disease and allied disorders. In: Holschneider AM, Puri P, eds. Hirschsprung's disease and allied disorders. Berlin: Springer Berlin Heidelberg 2008:387-396.

3. Catto-Smith AG, Coffey CMM, Nolan TM, et al. Fecal incontinence after the surgical treatment of Hirschsprung disease. J Pediatr Surg 1995;127:954-957.

4. Heij HA, de Vries X, Bremer I, et al. Long-term anorectal function after Duhamel operation for Hirschsprung's disease. J Pediatr Surg 1995;30: 430-432.

5. Bai Y, Chen H, Hao J, et al. Long-term outcome and quality of life after the Swenson procedure for Hirschsprung's disease. J Pediatr Surg 
2002;37:639-642.

6. Moore SW, Albertyn R, Cywes S. Clinical outcome and long-term quality of life after surgical correction of Hirschsprung's disease. J Pediatr Surg 1996;31:1496-1502.

7. Diseth TH, Bjornland K, Novik TS, et al. Bowel function, mental health, and psychosocial function in adolescents with Hirschsprung's disease. Arch Dis Child 1997;76:100-106.

8. Pensabene L, Youssef NN, Griffiths JM, et al. Colonic manometry in children with defecatory disorders. Role in diagnosis and management. Am J Gastroenterol 2003;98:1052-1057.

9. Mishalany HG, Woolley MM. Postoperative functional and manometric evaluation of patients with Hirschsprung's disease. J Pediatr Surg 1987;22:443-446.

10. Meinds RJ, Eggink MC, Heineman E, et al. Dyssynergic defecation may play an important role in postoperative Hirschsprung's disease patients with severe persistent constipation: analysis of a case series. J Pediatr Surg 2014;49:1488-1492.

11. Moore SW, Millar AJ, Cywes S. Long-term clinical, manometric, and histological evaluation of obstructive symptoms in the postoperative Hirschsprung's patient. J Pediatr Surg 1994;29:106-111.

12. Miele E, Tozzi A, Staiano A, et al. Persistence of abnormal gastrointestinal motility after operation for Hirschsprung's disease. Am J Gastroenterol 2000;95:1226-1230.

13. Van Leeuwen K, Geiger JD, Barnett JL, et al. Stooling and manometric findings after primary pull-throughs in Hirschsprung's disease: perineal versus abdominal approaches. J Pediatr Surg 2002;37:1321-1325.

14. Demirbag S, Tiryaki T, Purtuloglu T. Importance of anorectal manometry after definitive surgery for Hirschsprung's disease in children. Afr J Paediatr Surg 2013;10:1-4.

15. Zaslavsky C, Loening-Baucke V. Anorectal manometric evaluation of children and adolescents postsurgery for Hirschsprung's disease. J Pediatr Surg 2003;38:191-195.

16. Zakaria OM, El Labban GM, Shams ME. Fecal incontinence after single-stage Soave's pull-through: abdominal versus transanal endorectal pull-through. Ann Pediatr Surg 2012;8:5-8.

17. Rajindrajith S, Devanarayana NM, Benninga MA. Review article: faecal incontinence in children: epidemiology, pathophysiology, clinical evaluation and management. Aliment Pharmacol Ther 2013;37:37-48.

18. Tabbers MM, DiLorenzo C, Berger MY, et al. Evaluation and treatment of functional constipation in infants and children: evidence-based recommendations from ESPGHAN and NASPGHAN. J Pediatr Gastroenterol Nutr 2014;58:258-274.

19. Kim JH. How to Interpret Conventional Anorectal Manometry. J Neurogastroenterol Motil 2010;16:437-439.

20. Neuvonen MI, Kyrklund K, Rintala RJ, Pakarinen MP. Bowel function and quality of life after transanal endorectal pull-through for Hirschsprung disease: controlled outcomes up to adulthood. Ann Surg 2017256:33-629.

21. Gosemann JH, Friedmacher F, Ure B, Lacher M. Open versus transanal pull-through for Hirschsprung disease: a systematic review of longterm outcome. Eur J Pediatr Surg 2013;23:94-102.

22. Dickie BH, Webb KM, Eradi B, Levitt MA. The problematic Soave cuff in Hirschsprung disease: manifestations and treatment. J Pediatr
Surg 2014;49:77-80; discussion 80-81.

23. Levitt MA, Martin CA, Olesevich M, Bauer CL, Jackson LE, Peña A. Hirschsprung disease and fecal incontinence: diagnostic and management strategies. J Pediatr Surg 2009;44:271-277; discussion, 277.

24. Till H, Heinrich M, Schuster T, V Schweinitz D. Is the anorectal sphincter damaged during a transanal endorectal pull-through (TERPT) for Hirschsprung's disease? A 3-dimensional, vector manometric investigation. Eur J Pediatr Surg 2006;16:188-191.

25. Gad El-Hak NA, El-Hemaly MM, Negm EH, El-Hanafy EA, Abdel Messeh MH, Abdel Bary HH. Functional outcome after Swenson's pperation for Hirshsprung's disease. Saudi J Gastroenterol 2010;16:3034.

26. Lee TH, Bharucha AE. How to perform and interpret a high-resolution anorectal manometry test. J Neurogastroenterol Motil 2016;22:46-59.

27. Glia A, Gylin M, Akerlund J, Kindfors U, Lindberg G. Biofeedback training in patients with fecal incontinence. Dis Colon Rectum 1998;41:359-364.

28. Catto-Smith AG, Trajanovska M, Taylor RG. Long-term continence in patients with Hirschsprung's disease and Down syndrome. J Gastroenterol Hepatol 2006;21:748-753.

29. Powers MK, Brown ET, Hogan RM, Martin AD, Ortenberg J, Roth CC.Trends in toilet training and voiding habits among children with Down syndrome. J Urol 2015;194:783-787.

30. Holschneider AM, Steinwegs I. Functional diagnosis. In: Holschneider AM, Puri P, eds. Hirschsprung's disease and allied disorders. Berlin: Springer Berlin Heidelberg 2008:153-184

31. Rao SS, Patcharatrakul T. Diagnosis and treatment of dyssynergic defecation. J Neurogastroenterol Motil 2016;22:423-435.

32. Kumar D. An anatomical overview. In: Haslam J, Laycock JE, eds. Therapeutic management of incontinence and pelvic pain: pelvic organ disorders. London: Spinger-verlag 2007:187-197.

33. Langer JC. Persistent obstructive symptoms after surgery for Hirschsprung's disease: development of a diagnostic and therapeutic algorithm. J Pediatr Surg 2004;39:1458-1462.

34. Georgeson KE, Cohen RD, Hebra A, et al. Primary laparoscopicassisted endorectal colon pull-through for Hirschsprung's disease: a new dold standard. Ann Surg 1999;229:678-682; discussion 628-683.

35. Langer JC. Laparoscopic and transanal pull-through for Hirschsprung disease. Semin Pediatr Surg 2012;21:283-290.

36. Hyman PE. Defecation disorders after surgery for Hirschsprung's disease. J Pediatr Gastroenterol Nutr 2005;41(suppl 1):S62-S63.

37. Rao SS, Tuteja AK, Vellema T, Kempf J, Stessman M. Dyssynergic defecation: demographics, symptoms, stool patterns, and quality of life. J Clin Gastroenterol 2004;38:680-685.

38. Tjandra JJ, Chan MKY, Yeh CH, Murray-Green C. Sacral nerve stimulation is more effective than optimal medical therapy for severe fecal incontinence: a randomized, controlled study. Dis Colon Rectum 2008;51:494-502.

39. Brouwer R, Duthie G. Sacral nerve neuromodulation is effective treatment for fecal incontinence in the presence of a sphincter defect, pudendal neuropathy, or previous sphincter repair. Dis Colon Rectum 2010;53:273278 . 